\title{
L. Brown, Beckett, Lacan and the Voice
}

\section{Stefano Genetti}

\section{(Q) OpenEdition}

\section{Journals}

\section{Edizione digitale}

URL: http://journals.openedition.org/studifrancesi/10057

DOI: 10.4000/studifrancesi. 10057

ISSN: 2427-5856

\section{Editore}

Rosenberg \& Sellier

\section{Edizione cartacea}

Data di pubblicazione: 1 août 2017

Paginazione: 398

ISSN: 0039-2944

\section{Notizia bibliografica digitale}

Stefano Genetti, «L. Brown, Beckett, Lacan and the Voice», Studi Francesi [Online], 182 (LXI | II) | 2017,

online dal 01 août 2017, consultato il 05 janvier 2021. URL: http://journals.openedition.org/

studifrancesi/10057 ; DOI: https://doi.org/10.4000/studifrancesi.10057

\section{Questo documento è stato generato automaticamente il 5 janvier 2021}

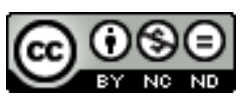

Studi Francesi è distribuita con Licenza Creative Commons Attribuzione - Non commerciale - Non opere derivate 4.0 Internazionale. 


\title{
L. Brown, Beckett, Lacan and the Voice
}

\author{
Stefano Genetti
}

\section{NOTIZIA}

LLEWELLYN BROWN, Beckett, Lacan and the Voice, Stuttgart, ibidem-Verlag, 2016, «Samuel Beckett in Company» 1, 433 pp.

1 A inaugurare una nuova collana beckettiana edita in Germania e presentata dal direttore Paul STEWART («Beckett and Relation: A Preface to the Series», pp. VII-XIII) è la lettura dell'intera opera di Beckett alla luce della psicoanalisi lacaniana condotta dal direttore, dapprima presso Minard, ora presso Classiques Garnier, della collana francese «Samuel Beckett». Complesso quanto rigoroso sul piano teorico-metodologico, lo studio si concentra sulla voce in quanto elemento incessante e fondante, ma anche poliedrico, paradossale persino, della creazione beckettiana: allo stesso tempo disincarnata e intrusiva, scissa dal soggetto del quale permea tuttavia le parole e la presenza, del soggetto la voce mette alla prova la resistenza, determinando una relazione vitale e creativa, ora violenta ora rasserenante, con il linguaggio, l'altro, il reale.

2 Sulla scorta del parallelo delineato da Jean-Michel RABATÉ nella prefazione («Lacan with Beckett: Departures», pp. XxIV-XXXv) a partire dal "Surrealismo involontario" di due sonetti del 1929-1930 - Tristesse Janale di Beckett e Hiatus irrationalis di Lacan -, nella sua ampia introduzione L. Brown sottolinea la centralità dell'udito e dell'ascolto, dell'ipersensibilità acustica ai rumori e al silenzio in quanto supporto sul quale i suoni si stagliano, al riecheggiare delle voci nella mente, all'enunciazione in quanto citazione, nonché alla problematizzazione identitaria che questa comporta, nell'insieme della scrittura eminentemente vocale di Beckett. Nell'isolare una serie di affinità che quest'ultima presenta rispetto alla teoria e alla pratica psicoanalitica lacaniana, dove la voce è concepita nella sua materialità, svincolata dalla significazione e atta a contrastare l'alterità distruttiva del Super-Io, l'A. introduce efficacemente all'accezione in cui Lacan ricorre a termini quali phonation ed énonciation, vocifération e invocation, 
équivoque ed extime, impossible e jouissance, insistendo sull'evacuazione del metalinguaggio e dell'opposizione binaria tra verità e finzione. Nel passare in rassegna altre letture lacaniane di Beckett, nonché la letteratura critica sulla voce in Beckett, egli mette in luce l'originalità di un approccio che, prendendo in considerazione l'evoluzione - inversioni di rotta comprese - del pensiero di Lacan, mira a superare non solo il dibattito su Beckett modernista o postmoderno, ma anche i limiti di un orientamento formalista oppure decostruzionista alla questione, valorizzando le implicazioni esistenziali della psicoanalisi. Intesa come una modalità di auscultazione dell'opera più che come un sapere precostituito che determina una griglia di lettura, la psicoanalisi, afferma l'A., permette di cogliere l'alterità radicale che caratterizza ogni esperienza umana e soggettiva, singolare, del linguaggio e di soffermarsi su ciò che, nel trattamento che Beckett riserva alla voce tra impedimento e reiterato fallimento, risulta irriconducibile a qualsivoglia processo logico-rappresentativo (pp. 36-37).

3 A partire da queste premesse, nei quattro capitoli in cui il lavoro è suddiviso, dedicati rispettivamente alla struttura della voce, agli slittamenti e alle disgiunzioni pronominali, alle reazioni che la tensione tra continuità e interruzione produce e all'esteriorità artificiale della voce, si susseguono le letture puntuali di temi e dispositivi ricorrenti: voci allucinate, persecutorie o consolatorie; voci non identificabili, illocalizzabili eppure inscritte, spersonalizzate eppure incorporate; voci udite e inudibili, interiorizzate e riprodotte; voci spettrali che riecheggiano in En attendant Godot come nei Textes pour Rien; voci foriere di immagini e voci che leggono, dando voce esse stesse al proprio altro da sé (pp. 225-240). Di volta in volta, le dialettiche io/non io, nominazione/vuoto, ascolto/sguardo, guidano l'interpretazione di opere che vanno da Murphy a Company/Comagnie, dalle pièces più note ai dramaticules - Not I/Pas moi, A Piece of Monologue/Solo e What Where/Quoi où, ad esempio - o al dramma televisivo Eh Joe/Dis Joe, dove il soggetto non cessa di dipendere dalla voce che lo tormenta. Sulla diversificazione dei mezzi tecnologici esplorati da Beckett, ci si sofferma in particolare nell'ultimo capitolo: se, in merito a Krapp's Last Tape/La dernière bande, l'ascolto meccanico della propria voce registrata, remota ed estranea, è visto come un disperato rituale offerto all'Altro per scongiurare la morte, le letture dei testi radiofonici, inclusi i frammenti, si arricchiscono costantemente di analogie con la narrativizzazione e con gli effetti performativi della voce nelle prose e nelle opere teatrali di Beckett.

Un'articolata Bibliografia e gli Indici - dei testi beckettiani, dei concetti psicanalitici e dei nomi - concludono un saggio la cui chiarezza argomentativa accompagna il lettore in un percorso di ascolto, tanto esigente quanto stimolante, delle molte voci all'opera in Beckett. 